\title{
Dynamic Analysis and Control of Supply Chain Systems
}

\author{
Alejandro Rodríguez-Angeles, América Morales Díaz and Arturo Sánchez \\ Centro de Investigación y de Estudios Avanzados \\ Depto. Ing. Electrica, Unidad Saltillo \& Unidad Guadalajara \\ México
}

\section{Introduction}

Globalization has changed in the last decade the shape of world trade, from independent and local markets to highly interrelated value chains demanding a large variety of goods with high quality standards. A supply chain is thus understood as a highly interconnected demand network composed of different stages or nodes that include raw materials, distributors of raw materials, manufacturers or producers, distributors of manufactured products, retailers and customers. Between these stages or nodes there is an interchange of information (orders) and flows of materials. The above mentioned elements of a supply chain and their relations give rise to complex structures, whose interactions affect the performance of the entire system.

Nowadays the markets require flexibility, speed and productivity in order to satisfy an environmentally-conscious consumer demanding a larger variety of manufactured goods. These trade conditions impose low costs and effectiveness in production. Therefore, most supply chains strive for minimizing raw material and finished products inventories in fast distribution networks (Fujimoto, 2002), (Steidtmann, 2004) while fulfilling astringent manufacturing rules. This tendency has resulted on what is called synchronization of production and distribution at the supply chain. Supply chain synchronization occurs when the consumer business world is linked together by technology, making each of the constitutive parts, consumers, suppliers, producers, associates and distributors synchronize with the whole. Thus, when the consumer places a request for an end-product, there is a synchronized retailer or distributor there to deliver it. For example (Koudal, 2003) studied the demand and supply dynamics in the automotive value chain, yielding flexibility and fast consumer respond. In textile industry, TAL Appareal Group applied electronic and communications platforms to evolve into a flexible manufacturer, growing from a single local textile mill to a global multinational company (Koudal \& Wei-teh, 2005). From an economic point of view the potential impact of performance improvements on production systems is tremendous.

The arising dynamics complexity of highly synchronized supply chains poses demanding control challenges for their operation and management, for which representative models are required. Two decision levels can be considered in the supply chain operation: the first is the tactical and is referred to the decision making process that optimizes the supply chain performance, and the second involves the operational activities. A well-constructed supply 
chain model, either for the tactical or operative levels, must preserve relevant information associated with the flow and transformation of raw materials to finished products and their distribution to the consumers.

Several approaches in supply chain modelling have been considered, from quantitative models (Tayur et al., 1998) to fuzzy models (Petrovic et al., 1999). Extensive overviews can be found in (Daganzo, 2002) and (Shapiro, 2007). Most of the proposed supply chain models are deterministic, nonetheless there are a few that takes into account demand uncertainty in an stochastic framework (e.g. Lababidi et al., 2004) .

Supply chain management has been extensively studied. Most works focused on the tactical area and mainly deal with production planning and scheduling. In planning and scheduling of supply chains one of the goals is to determine the inventory levels to satisfy the market demands in a timely and cost effective manner. Inventory levels planning and orders handling are addressed in (Perea et al., 2001) and (Cetinkaya \& Lee, 2000). In (Perea et al., 2001) a dynamic model based on balances of inventories and orders is presented, together with a decentralized decision making process that considers production policies. The same model is used in (Perea et al., 2003) to develop a model predictive control strategy, improving the planning forecast in a time horizon.

Some others works are focused on the supply chain dynamics and its operational level. In (Lin et al. 2004) an analysis and control for bullwhip effect is presented based on ztransform. By using traffic dynamics (Nagatani \& Helbing, 2003) proposed a continuous time dynamic model to represent the behaviour of the inventories and the production rates. Moreover a control strategy and production policies to bring an unstable system into the stable region are proposed. The aim is to control the production rates, while inventories are, to some extend, free to evolve in a bounded region, which may result in unsuitable stock levels regarding a reliable and competitive performance of the system. Analytical conditions for absolute and convective instabilities were presented in (Helbing et al., 2004). Finally, for the dynamic management of supply chain networks, (Dunbar \& Desa, 2005) demonstrated the application of nonlinear distributed model predictive control strategies. (Lefeber, 2004) also considers traffic flow theory to propose a supply chain model based on differential equations, taking into account delays on handling orders and inventory level dynamics.

This chapter is focused on the operational activities of the supply chain dynamics. Similarly to those works developed in (Perea et al., 2001), (Helbing et al., 2004) and (Lefeber, 2004), dynamic models for multipurpose systems are proposed considering production ratios. First a dynamic model dealing only with material flows is introduced, and then it is extended to consider order flows and delays on handling materials and orders. In agreement with physical limitations, bounds in the inventory levels and flow rates are taken into account. Once the models are introduced, a bounded and smooth controller is proposed. This controller regulates the inventory levels while synchronizing the flows at the whole supply chain system. Closed loop convergence to desired inventory levels and production rates stability is proved. The proposed modelling and control techniques are applied to two simulation case studies: a petrochemical multiproduct plant and a crude oil blending and distribution system. The chapter closes with some general conclusions and trends in supply chain systems.

\section{Supply chain dynamic models}

A supply chain model must capture relevant activities associated with the inventory levels, and the flow and transformation of good from the raw material stage to the final costumer. 
The entities that may form a supply chain, i.e. suppliers, distributors, producers, etc., they can be classified as producer or non producer nodes. The main difference among them is that producer nodes may vary their production ratio, thus varying its inventory level. Non producer nodes may vary their inventory levels only by ordering from upstream entities.

Although inventory and material flow dynamics may be enough for modelling some supply chain systems, there are situations in which information flows, such as orders, are needed to properly represent the system dynamics. This section presents both types of models, one entirely based on inventory levels and material flows, and one that considers orders handling.

\subsection{Linear supply chain systems: material flow rate model}

The models are based on macroscopic mass balance equations. Therefore the mass variation is equal to the difference between the material inflow and outflow rate (see Figure 1) and is represented by equation (1). These models represent systems in which the material delivery flow rate corresponds exactly and without delay to the demanded one. Notice that the above considerations render linear dynamic models based on differential equations.

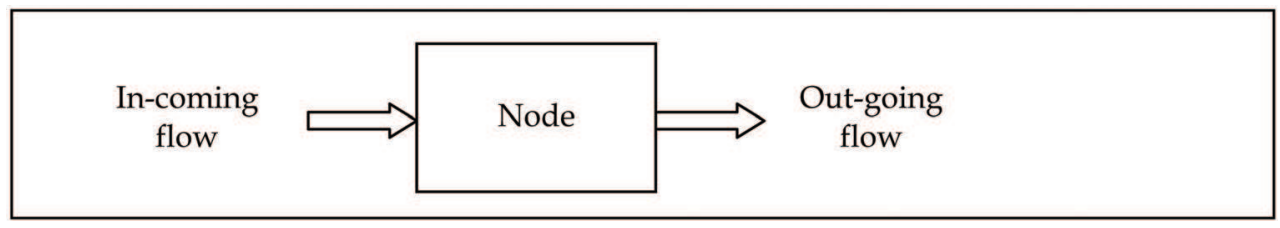

Fig. 1. Mass balance representation in a supply chain node.

By considering the dynamics on the properties of interests, i.e. inventory levels and material flows, a supply chain consists from n-nodes, with inventory levels $N_{i}$, for $i=1, \ldots, n$, and depending if the node is a producer or not, a production or incoming flow rate $\lambda_{i}$; as it is depicted in Figure 2.

The change in the inventory level is represented by the difference between the production or incoming rate $\lambda_{i}$, depending whether it is a producer or non producer node respectively, and the delivery flow rate $\lambda_{d_{-} p, i}$.

$$
\frac{d N_{i}}{d t}=\lambda_{i}-\lambda_{d_{-} p, i}
$$

Where $\lambda_{d_{-} p, i}$ represents the total demand of products to node $i$, and considers the demand of all the $r$ nodes requiring products or material from node $i$, with individual demanding rates $\lambda_{i}$ and with the product ratio $F_{i, j}$, this is

$$
\lambda_{d_{-} p, i}=\sum_{j=1}^{r} F_{i, j} \lambda_{j}
$$

The product ratio $F_{i, j}$ allows modelling multipurpose or multiproduct systems. The product ratios represent the amount of product $i$ that is required by the $j$-node to produce a unit of product. The product ratio allows changing recipes or product proportion, such that 
different products can be easily considered. Furthermore, these product ratios define the synchronized behaviour among the material flows at the supply chain.

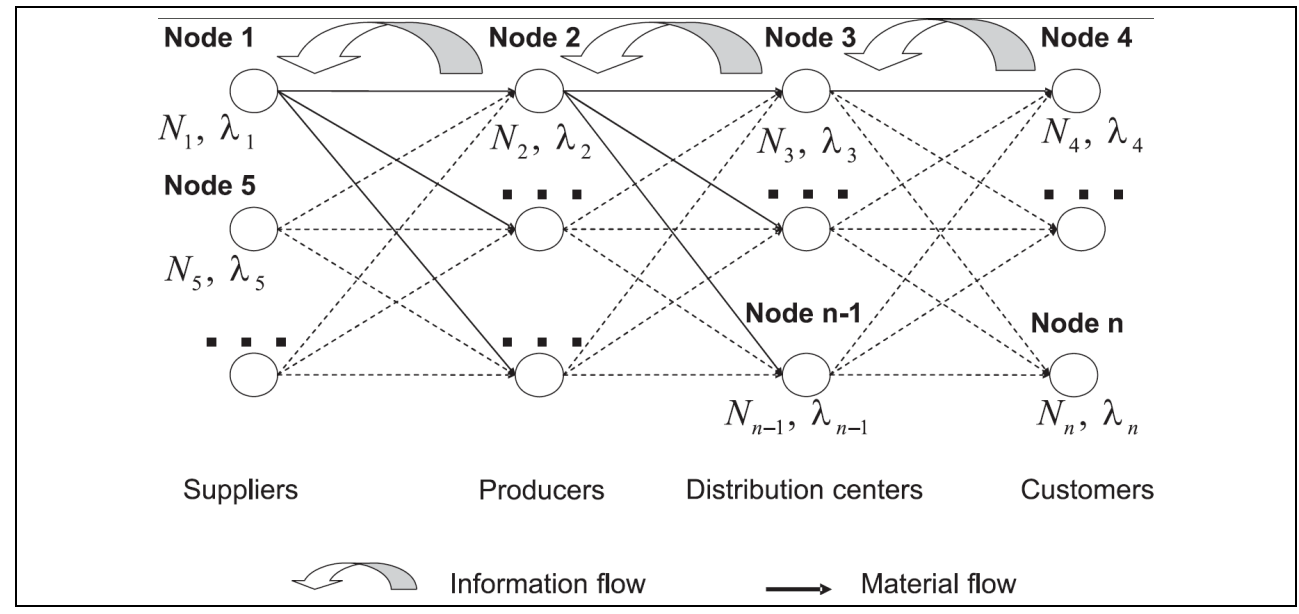

Fig. 2. Inventories, information and material flow in a supply chain.

The production or incoming rate $\lambda_{i}$ constitutes the control action to vary the inventory dynamics in a node- $i$, whether it is a producer or non producer node respectively.

For a non producer node its incoming rate corresponds only to the product or materials that are received from its suppliers. Contrary, in a producer node the production rate varies accordingly to production policies and posses dynamical behaviour. In a producer node a change in the production rate involves several activities that require an adaptation time $T_{i}$. Moreover, if $\mathrm{W}_{\mathrm{i}}$ denotes the control action that varies the production rate $\lambda_{i}$ in a producer node, then its dynamics can be represented by

$$
\frac{d \lambda_{i}}{d t}=\frac{1}{T_{i}}\left(\mathrm{~W}_{\mathrm{i}}-\lambda_{i}\right)
$$

Notice that because of physical or operational boundedness of the system the inventories, production and incoming rates, must be bounded accordingly, this is

$$
\begin{aligned}
& N_{i, \min } \leq N_{i} \leq N_{i, \max } \\
& 0 \leq \lambda_{i} \leq \lambda_{i, \max }
\end{aligned}
$$

where $N_{i, \min }, N_{i, \max }$ are the minimum and maximum allowed inventory level respectively, and $\lambda_{i, \max }$ is the maximum production or incoming rate.

In case of producer nodes, their dynamics includes inventory levels and production rate, thus, they are modelled by equations (1), (2) and (3). Meanwhile for non producers only inventory levels dynamics (1) and (2) are considered, which vary thru ordering products or material from upstream nodes.

The model represented by equations (1)-(4) disregard delivering delays, nevertheless, the adaptation time $T_{i}$ plays a role that induces a kind of delay. The adaptation time parameter $T_{i}$ allows reproducing bullwhip phenomena among other phenomena in this type of model. 
At model (1), (2), (3) and (4) raw materials storage at a producer node is consider as an independent entity, which renders extra degrees of freedom to the system regarding control policies. This consideration establishes an advantage and at the same time a challenge that allows regulating inventory levels and simultaneously supply chain synchronization.

The consumer demand is the variable that imposes the policy operation and is traduced to flow rates for each node, taking into account the production ratios $F_{i, j}$. For example, in the automotive supply chain several types of cars have to be built, the net flow of finished cars per time unit is the costumer demand. But at upstream entities of the supply chain this is traduced in the corresponding part rate, e.g. 4 wheels and one motor per car, and so on.

\subsection{Nonlinear supply chain systems: orders flow model}

A supply chain as that depicted in Figure 2 includes information flows, particularly orders among downstream and upstream entities. In some situations such information flows have to be taken into account, either to strive for performance improvement or because not all orders are fulfil immediately, then an unattended orders balance appears.

Accumulation of material $N_{i}$ and unattended orders $O_{i}$ can be modelled similarly as balances between incoming and outgoing flows as follows

$$
\begin{aligned}
& \frac{d N_{i}}{d t}=\lambda_{i}-y_{i} \\
& \frac{d O_{i}}{d t}=\delta_{i}-y_{i}
\end{aligned}
$$

Where $y_{i}$ represents the shipped product (attended orders) and $\delta_{i}$ represents the total product demanding rate, which correspond to all orders requiring product or material from the $i$ th-node. Similarly to the total product demand (2) product ratios $F_{i, j}$ may be considered, this is

$$
\delta_{i}=\sum_{j=1}^{r} F_{i, j} \lambda_{j}
$$

In the above model representation (5), (6), when an order is put in node $i$, it will take an interval of time until it is attended, this is represented by a time delay parameter denoted by $\tau_{i}$. Furthermore, following traffic flow theory (Lefeber, 2005) a shipping function that depends on the inventory level and the accumulated orders is introduced, this is

$$
y_{i}=\frac{N_{i}}{\left(N_{i}+1\right)} \frac{O_{i}}{\tau_{i}}
$$

Equation (7) reflects the outgoing product rate in node $i$ and it is bounded from below by $y_{i} \geq 0$, thus only positive flows are allowed. The outgoing product policy depends on inventory level $N_{i}$ such that the product will be shipped only if there is in stock. Since (7) is a nonlinear function on $N_{i}$, then the resulting supply chain model is of nonlinear type.

The production rate $\lambda_{i}$ in a producer node, as in the case of model (1), (2), (3) and (4), varies accordingly to production policies. Therefore the dynamics in the flow rate is the same as in 
equation (3). For simplicity in case of producer nodes it is assumed that upstream nodes deliver the demanded product or material as soon as it is required for production; this is a producer has storage facilities which guarantee the required materials. Then these storage facilities are the ones that can have unattended orders from their suppliers. Furthermore, it is considered that producer nodes modify its production rate to deliver the material amount that is required such that orders accumulation is not an issue in a production facility. Then a producer node is modeled by equation (5), (3), and (7) with $y_{i}=\delta_{i}$.

For non producer nodes, their dynamics is given only by inventory levels and balance of unattended order, equations (6) and (7). Therefore accumulation of unattended orders appears only in non producer nodes.

\section{Supply chain regulation, control strategies}

When regulating the supply chain dynamics, the goal is to establish flow rates that guarantee that the inventory levels reach and keep a desired level, while a final costumer demand is satisfied. On the other hand, as it was mentioned the supply chain must satisfy physical constraints, such as bounded inventory levels, and maximum production or incoming flow rates, see equation (4). Therefore the control actions to regulate the supply chain must be designed taking into account such constraints.

This section presents two bounded control strategies for inventory regulation and flow rate synchronization. For these purposes PI techniques are considered to vary the production or incoming flow rates. Stability is proved by standard analysis based on linearization theory and pole placement techniques. First the controller for linear supply chain systems is presented and then it is extended for nonlinear supply chains.

\subsection{Control strategy by flows variation}

For producer nodes, variation on the production rate $\lambda_{i}$, whose dynamics is given by equation (3), is achieved by the control action or production policy $W_{i}$. Meanwhile for non producer nodes, inventory levels regulation is achieved by direct variation of their incoming flow rates $\lambda_{i}$. For each of these two classes of systems similar control actions are proposed as follows.

Since the production rate $\lambda_{i}$ in $(2,3)$ is bounded by $(4)$, then the control action must be bounded accordingly at a producer node, this is

$$
0 \leq W_{i} \leq \lambda_{i, \max }
$$

To satisfy the above constraint the control action $W_{i}$ for a producer node is proposed as

$$
W_{i}=\lambda_{i, \max }\left(2-\frac{1}{1+e^{-\alpha_{i}\left(N_{i}-N_{c, i}\right)}}-\frac{1}{1+e^{-\alpha_{i} N_{c, i}}}\right)
$$

Meanwhile for a non producer node its inventory dynamics (1) is modified by its incoming rate $\lambda_{i}$, such that it is proposed to vary as

$$
\lambda_{i}=\lambda_{i, \max }\left(2-\frac{1}{1+e^{-\alpha_{i}\left(N_{i}-N_{c, i}\right)}}-\frac{1}{1+e^{-\alpha_{i} N_{c, i}}}\right)
$$


where $\lambda_{i, \max }$ is the maximum production or incoming rate in the node, see (4), $\alpha_{i}$ is a parameter that regulates the convergence rate of $N_{i}$. The larger $\alpha_{i}$, the faster the convergence rate of $N_{i}$ to its desired value $N_{d, i}$. However, too large values of $\alpha_{i}$ can induce instability. $N_{c, i}$ is proposed as a modified PI control, it acts as a nominal reference and forces $N_{i}$ to a desired constant value $N_{d, i}$. $N_{c, i}$ allows introduction of several production policies as the ones presented in (Helbing, 2003).

$$
N_{c, i}=N_{d, i}-K_{P, i}\left(N_{i}-N_{d, i}\right)-K_{I, i} \int\left(N_{i}-N_{d, i}\right) d t
$$

Where $K_{P, i}$ and $K_{I, i}$ are the positive proportional and integral control gains, respectively. The integral action renders a steady error equal to zero around the equilibrium point, while the proportional action regulates the convergence rate.

The controllers (9) and (10) use exponential functions to render a bounded control action, while allowing a smooth and fast convergence. The term in between parenthesis is bounded in $[0,1]$, after multiplying this term by $\lambda_{i, \max }$, the physical and operational limitations on the production or incoming rate, see (4), are recovered.

\section{Stability analysis}

The goal of this section is to establish closed loop stability and synchronization conditions for the supply chain at an equilibrium point.

The controllers (9) and (10) induce nonlinearities in the closed loop system, so that, linearization techniques are considered for the stability analysis.

Theorem 1

The equilibrium point $\left(\lambda_{i}^{*}, N_{i}^{*}\right)$ of the closed loop formed by a producer node (1 - 3) and (9) is given by $\lambda_{i}^{*}=\lambda_{d_{-} p, i}$ for the production rate, and $N_{i}^{*}=N_{d, i}$ for the inventory level. Meanwhile, the closed loop of a non producer node (1) and (10) implies the same equilibrium point as for a producer node, it is $\lambda_{i}^{*}=\lambda_{d_{-} p, i}$ and $N_{i}^{*}=N_{d, i}$.

Proof:

First for a producer node, from (1) and (3) it follows that the equilibrium conditions are

$$
0=\lambda_{i}^{*}-\lambda_{d-p, i} \quad 0=\frac{1}{T_{i}}\left(W_{i}-\lambda_{i}^{*}\right)
$$

thus $\lambda_{i}^{*}=\lambda_{d_{-} p, i}$ and simultaneously $W_{i}=W_{i}\left(N_{i}^{*}\right)=\lambda_{i}^{*}$ such that $W_{i}\left(N_{i}^{*}\right)$ must be constant. By substitution of (9) and (11), it follows that because $\lambda_{i, \max }$ and $\alpha_{i}$ are constants, then $W_{i}\left(N_{i}^{*}\right)$ is constant if and only if $N_{i}^{*}=N_{d, i}$.

A similar analysis allows concluding the closed loop equilibrium point for non producer nodes.

Note that the equilibrium point of both producer and non producer nodes implies that $\lambda_{i}^{*}=\lambda_{d_{-} p, i}$, therefore $\lambda_{i}$ synchronizes with the total demanding rate $\lambda_{d_{-} p, i}$, given by equation (2), and such that instantaneous consumption and supply chain synchronization are achieved. Simultaneously the inventory levels fulfills $N_{i}^{*}=N_{d, i}$, thus inventory regulation is obtained.

Theorem 2

The closed loop system formed by a producer node (1 - 3) with the controller (9) and (11) is locally asymptotically stable and converge to the equilibrium point $\lambda_{i}^{*}=\lambda_{d_{-} p, i}$ and $N_{i}^{*}=N_{d, i}$, if the gains $\alpha_{i}, K_{P, i}$, and $K_{I, i}$ satisfy 


$$
\begin{gathered}
\alpha_{i} \geq 1 \\
\zeta_{1} \leq K_{P, i}<\zeta_{2} \\
0<K_{I, i} \leq \frac{1}{4} \frac{K_{P, i}}{T_{i}} \\
\zeta_{1}=\left|\frac{\left(1+e^{-\left(\alpha_{i} N_{d, i}\right)}\right)^{2}\left(\alpha_{i} \lambda_{i, \max } T_{i}-1\right)}{\alpha_{i} \lambda_{i, \max } T_{i}\left(e^{-\left(\alpha_{i} N_{d, i}\right)}-1\right)^{2}}\right| \\
\zeta_{2}=\left|\frac{\left(1+e^{-\left(\alpha_{i} N_{d, i}\right)}\right)^{2}}{\left(\left(e^{-\left(\alpha_{i} N_{d, i}\right)}-1\right)^{2}\right.}\right|
\end{gathered}
$$

Furthermore, the above conditions ensure an overdamped closed loop system, (i.e. the eigenvalues are negative and purely real), avoiding large overshoots and keeping physical and operations constraints given by (4).

Proof:

In the equilibrium point $\lambda_{i}^{*}=\lambda_{d_{-} p, i}, N_{i}^{*}=N_{d, i}$, the closed loop is linearize around small deviations $\delta \lambda_{i}$ and $\delta N_{i}$ as

$$
\dot{x}=\left[\begin{array}{cc}
0 & 1 \\
\frac{1}{T_{i}} W_{i}^{\prime}\left(N_{i}^{*}\right) & -\frac{1}{T_{i}}
\end{array}\right] x
$$

where $x=\left[\begin{array}{ll}\delta N_{i} & \delta \lambda_{i}\end{array}\right]^{T}$ and whose eigenvalues $s_{1,2}$ are given by

$$
s_{1,2}=\frac{-\frac{1}{T_{i}} \pm \sqrt{\frac{1}{T_{i}^{2}}+\frac{4}{T_{i}} W_{i}{ }^{\prime}\left(N_{i}^{*}\right)}}{2}
$$

Then the closed loop is asymptotically stable and overdamped if the derivative of the control function $W_{i}{ }^{\prime}\left(N_{i}^{*}\right)$ fulfills

$$
-\frac{1}{4 T_{i}} \leq W_{i}^{\prime}\left(N_{i}^{*}\right)<0
$$

which imposes conditions on $\alpha_{i}, K_{P, i}$, and $K_{I, i}$. Replacing (11) in (9) yields

$$
W_{i}{ }^{\prime}\left(N_{i}^{*}\right)=\alpha_{i} \lambda_{i, \max }\left(-\frac{1}{4}\left(1+K_{P, i}+t K_{I, i}\right)+\frac{\left(K_{P, i}+t K_{I, i}\right) e^{-\left(\alpha_{i} N_{d, i}\right)}}{\left(1+e^{-\left(\alpha_{i} N_{d, i}\right)}\right)^{2}}\right)
$$


where $t$ represents the integration time. When $N_{i}^{*}=N_{d, i}$ there is not integral action, thus it can be taken $t=0$, and from (19) and by algebraic manipulation it follows that sufficient conditions on $K_{P, i}$, for (18) being satisfied, are given by (14).

By defining the regulation error $e_{i}=N_{i}-N_{d, i}$, replacing it in (11) and taking first derivative with respect to time it is obtained

$$
\frac{d N_{c, i}}{d t}=-\alpha_{i} K_{P, i} \frac{d e_{i}}{d t}-K_{I, i} e_{i}
$$

In the equilibrium point $N_{i}$ becomes constant, i.e. $N_{i}^{*} \rightarrow N_{d, i}$, thus (20) equals to zero and by Laplace transform it is obtained the pole

$$
\frac{d N_{c, i}}{d t}=-\alpha_{i} K_{P, i} \frac{d e_{i}}{d t}-K_{I, i} e_{i}
$$

Considering that the pole in (21) must verify condition (18) to limit the dynamics of the closed loop, then $K_{I, i}$ must satisfy condition (15).

Finally, since only $K_{P, i}$ through the condition (14) depends on $\alpha_{i}$, it can be to some extend freely chosen. Thus for convenience and to obtain fast convergence it is taken that $\alpha_{i}>1$.

\section{Theorem 3}

The closed loop system formed by a non producer node (1) with the controller (10) is locally asymptotically stable and converge to the equilibrium point $\lambda_{i}^{*}=\lambda_{d_{-} p, i}$ and $N_{i}^{*}=N_{d, i}$, if the gains $\alpha_{i}, K_{P, i}$, and $K_{I, i}$ satisfy

$$
\begin{gathered}
\alpha_{i} \geq 1 \\
K_{P, i}<\left|\frac{\left(1+e^{-\left(\alpha_{i} N_{d, i}\right)}\right)^{2}}{\left(e^{-\left(\alpha_{i} N_{d, i}\right)}-1\right)^{2}}\right| \\
K_{I, i}>0
\end{gathered}
$$

Furthermore, the above conditions ensure an overdamped closed loop system.

Proof:

It follows as for Theorem 2

\subsection{Control strategy by orders and flows handling}

Due to the similarities between the models for linear supply chain systems $(1-4)$ and the model that considers orders handling $(5,6,3$ and 7$)$, the controllers $(9,10$ and 11) still apply. This section shows that the unattended orders modify the closed loop equilibrium point and the value conditions on the control gains, but the control architecture $(9,10$ and 11) is robust enough to deal with order handling and the implicit delays modelled by the shipping function $y_{i}$ given by (7) and the production adaptation parameter $T_{i}$.

Stability analysis

The stability analysis follows as the one presented in Section 3.1, first the equilibrium point is determined and then stability and convergence conditions are provided. 


\section{Theorem 4}

The equilibrium point $\left(\lambda_{i}^{*}, N_{i}^{*}\right)$ of the closed loop formed by a producer node (5), (3), and (7) with $y_{i}=\delta_{i}$, and the controller (9) is given by $\lambda_{i}^{*}=\delta_{i}$ for the production rate, and $N_{i}{ }^{*}=N_{d, i}$ for the inventory level. Meanwhile, the closed loop of a non producer node (5), (6), (7), and (10) posses the equilibrium point $\lambda_{i}^{*}=\delta_{i}, \quad N_{i}^{*}=N_{d, i}$, $O_{i}^{*}=\left[\delta_{i} \tau_{i}\left(N_{d, i}+1\right)\right] / N_{d, i}$.

Proof:

Follows as the proof of Theorem 1, with the supply chain dynamics equal to zero.

Theorem 5

The closed loop system formed by a producer node (5), (3), and (7) with $y_{i}=\delta_{i}$, and the controller (9) is locally asymptotically stable and converge to the equilibrium point $\lambda_{i}^{*}=\delta_{i}$, $N_{i}^{*}=N_{d, i}$ if the gains $\alpha_{i}, K_{P, i}$, and $K_{I, i}$ satisfy

$$
\begin{gathered}
\alpha_{i}>0 \\
\zeta_{3} \leq K_{P, i} \\
0<K_{I, i}<\frac{K_{P, i} W_{i}\left(N_{d, i}\right)}{N_{d, i}\left(1+N_{d, i}\right)} \\
\zeta_{3}=\left|\frac{\left(1+e^{-\left(\alpha_{i} N_{d, i}\right)}\right)^{2}\left[\left(\alpha_{i} \lambda_{i, \max } N_{d, i}\left(N_{d, i}+1\right)\right)-4 W_{i}{ }^{\prime}\left(N_{d, i}\right)\right]}{\alpha_{i} \lambda_{i, \max } N_{d, i}\left(N_{d, i}+1\right)_{i}\left(e^{-\left(\alpha_{i} N_{d, i}\right)}-1\right)^{2}}\right|
\end{gathered}
$$

With $W_{i}{ }^{\prime}\left(N_{d, i}\right)$ as in (19). Furthermore, the above conditions ensure an overdamped closed loop system, avoiding large overshoots and keeping physical and operations constraints given by (4).

Proof:

Follows as for Theorem 2 with

$$
\dot{x}=\left[\begin{array}{cc}
-\frac{W_{i}\left(N_{d, i}\right)}{N_{d, i}\left(N_{d, i}+1\right)} & 1 \\
\frac{1}{T_{i}} W_{i}{ }^{\prime}\left(N_{i}^{*}\right) & -\frac{1}{T_{i}}
\end{array}\right]^{x}
$$

Then by evaluating the system eigenvalues it follows that the closed loop is asymptotically stable and overdamped, if the following condition fulfills

$$
\frac{W_{i}\left(N_{d, i}\right)}{N_{d, i}\left(N_{d, i}+1\right)}-W_{i}{ }^{\prime}\left(N_{d, i}\right) \leq 0
$$

The rest of the proof follows as for Theorem 2, yielding the stability and convergence conditions (25), (26) and (27). 
Theorem 6

The closed loop system formed by a non producer node (5), (6) and (7) with the controller (10) is locally asymptotically stable and converge to the equilibrium point $\lambda_{i}^{*}=\delta_{i}$, $N_{i}^{*}=N_{d, i}$ and $O_{i}^{*}=\left[\delta_{i} \tau_{i}\left(N_{d, i}+1\right)\right] / N_{d, i}$, if the gains $\alpha_{i}, K_{P, i}$, and $K_{I, i}$ satisfy

$$
\begin{gathered}
\alpha_{i}>0 \\
K_{P, i} \leq\left|\frac{\left(1+e^{-\left(\alpha_{i} N_{d, i}\right)}\right)^{2}\left[\left(\alpha_{i} \lambda_{i, \max } N_{d, i}\left(N_{d, i}+1\right)\right)-4 \lambda_{i}{ }^{\prime}\left(N_{d, i}\right)\right]}{\alpha_{i} \lambda_{i, \max } N_{d, i}\left(N_{d, i}+1\right)_{i}\left(e^{-\left(\alpha_{i} N_{d, i}\right)}-1\right)^{2}}\right| \\
K_{I, i} \leq \frac{K_{P, i} \phi}{N_{d, i}\left(N_{d, i}+1\right)} \\
\phi=2 \sqrt{\tau_{i} N_{d, i}\left[N_{d, i}{ }^{2}\left(1-\tau_{i}\right)+\tau_{i} \lambda_{i}\left(N_{d, i}\right)\right]}+N_{d, i}{ }^{2}\left(1-2 \tau_{i}\right)+\lambda_{i}\left(N_{d, i}\right)
\end{gathered}
$$

Furthermore, the above conditions ensure an overdamped closed loop system.

Proof:

It follows as for Theorem 5 .

\section{Study case application}

At this section the modelling and control techniques proposed in sections 2 and 3 are applied to a simulation case study. For the linear supply chain a multiproduct petrochemical plant is considered. Meanwhile, for the nonlinear supply chain with orders handling an extraction, blending and distribution system for crude oil is studied.

\subsection{Linear supply chain: multiproduct petrochemical plant}

The proposed modelling and controller techniques for linear supply chains, Sections 2.1 and 3.1 , are tested by simulations on a multi-product petrochemical company, which produces different grades of polyethylene products, see Figure 3. The numbers on the left upper side of the nodes identifies the numbering used through the simulations and figures presenting plots of the results.

Hexane and catalyst are imported, whereas ethylene is obtained from a local refinery. The production of ethylene and butane is carried out by independent production plants. There exist intermediate storages for the hexane, ethylene, butane and catalyst feedstocks. Only five demand sources are taken into consideration, from D1 to D5. The reactors R1 and R2 produce different polymeric products depending on the fed material (production ratio) and operation conditions. Each reactor produces two polymers: R1 produces A1 and A2, and R2 produces B1 and B2 in a cyclic way, according to a given schedule; R1, R2 and their storages are of multi-product kind, thus have different stocks per product. For supply chain synchronization, it is considered that the demanded product is supplied to the costumer only during the production time of the corresponding product. 


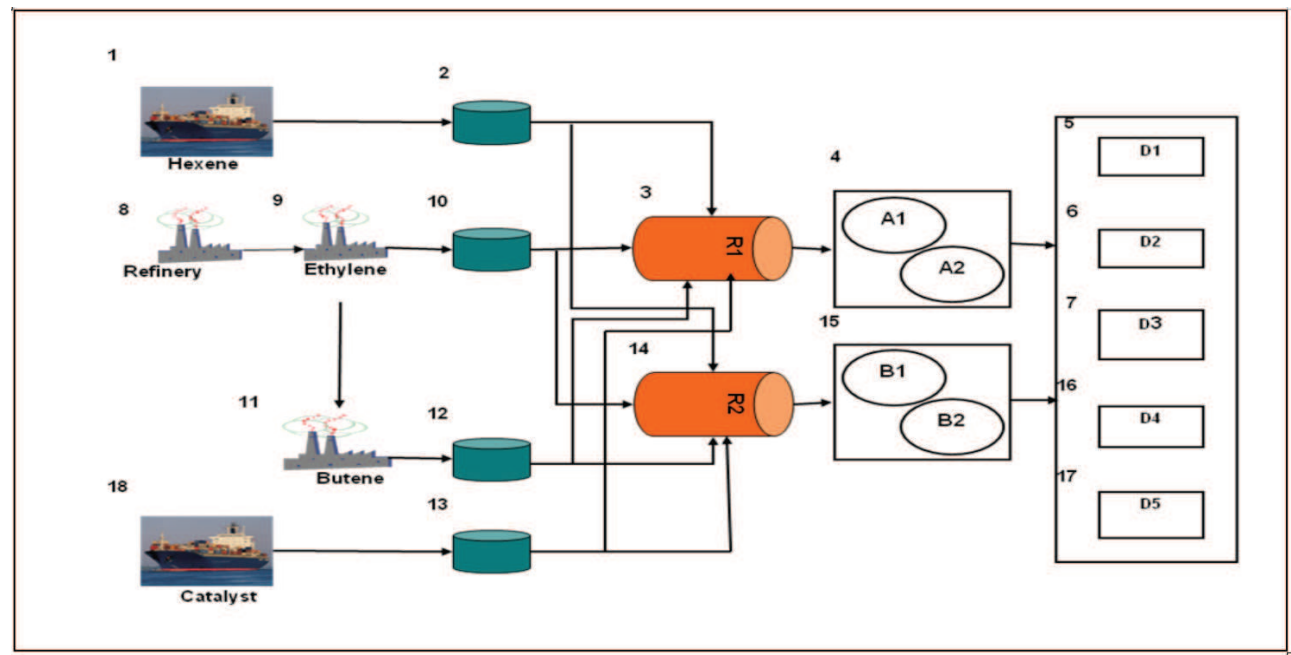

Fig. 3. Supply chain for a multi-product polyethylene petrochemical plant

The simulated period is $10 \mathrm{hrs}$. Reactors R1 and R2 change from producing product A1 to $\mathrm{A} 2$ and $\mathrm{B} 2$ to $\mathrm{B} 1$ at $\mathrm{t}=5 \mathrm{hrs}$ respectively. The production ratios and demands for the four products are listed in Table 1. The rest of the production ratios are independent of the kind of product, such that $F_{8,9}=1.5$ and $F_{9,11}=0.8$, and those for storage purposes are all equal to 1 . The plant capacity per reactor is 34.24 [MT/hr].

For reactor R1 and product A1 a desired inventory level of $N_{d, 3}=400$ is considered, while for product A2, $N_{d, 3}=395$. For the distributor of products A1 and A2, $N_{d, 4}=440$ for A1 and $N_{d, 4}=420$ for A2. Similarly for reactor R2 and its distributor $N_{d, 14}=420$ and $N_{d, 15}=1000$ for B1, $N_{d, 14}=420$ and $N_{d, 15}=1300$ for B2.

\begin{tabular}{|c|c|c|c|c|c|}
\hline & A1 & A2 & & B1 & B2 \\
\hline$F_{2,3}$ & 0.25 & 0.4 & $F_{2,14}$ & 0.6 & 0.4 \\
\hline$F_{10,3}$ & 0.15 & 0.2 & $F_{10,14}$ & 0.15 & 0.1 \\
\hline$F_{12,3}$ & 0.5 & 0.3 & $F_{12,14}$ & 0.1 & 0.3 \\
\hline$F_{13,3}$ & 0.2 & 0.1 & $F_{13,14}$ & 0.15 & 0.2 \\
\hline$D_{1}$ & 5 & 8 & $D_{4}$ & 9 & 14 \\
\hline$D_{2}$ & 3 & 6 & $D_{5}$ & 13 & 8 \\
\hline$D_{3}$ & 12 & 11 & & & \\
\hline
\end{tabular}

Table 1. Demands in $[\mathrm{MT} / \mathrm{hr}]$ and production ratios for products A1, A2, B1 and B2.

The storage capacity of the plant is of 2000 [MT] for nodes 2, 10, and 12; 10000 [MT] for nodes 4, 13 and 15; and for nodes 3, 8, 9, 11 and 14 of 500 [MT]. According to a monthly schedule with daily resolution, inventory levels on nodes 1 and 13 must be of 3000 [MT] and 2500 [MT], respectively. The desired inventory levels for the rest of the nodes are listed in Table 2. Note that the planning or scheduling instance must take into account the physical and operational limitations listed in Table 2 to provide feasible and attainable inventories. 
The initial values at $\mathrm{t}=0 \mathrm{hrs}$ and the operational limitations are listed in Table 2 . For the multi-product reactor R1 its initial values are for product A1 $N_{3}(0)=405$, while for product $\mathrm{A} 2, N_{3}(0)=390$. For the distributor the initial values are $N_{4}(0)=435$ for $\mathrm{A} 1$ and $N_{4}(0)=425$ for A2. Similar for R2 and its distributor the initial values are $N_{14}(0)=385$ and $N_{15}(0)=990$ for B1, $N_{14}(0)=415$ and $N_{15}(0)=1310$ for B2.

\begin{tabular}{|c|c|c|c|c|c|c|c|c|c|c|c|c|}
\hline Node & 1 & 2 & 3 & 4 & 8 & 9 & 10 & 11 & 12 & 13 & 14 & 15 \\
\hline$N_{i}(0)$ & 3000 & 992 & & & 377 & 377 & 360 & 356 & 360 & 2500 & & \\
\hline$\lambda_{i}(0)$ & & & 24 & & 36 & 39 & & 33 & & & 22.8 & \\
\hline$T_{i}$ & & & 0.5 & & 0.1 & 0.1 & & 0.2 & & & 0.1 & \\
\hline$\lambda_{i, \max }$ & & 120 & 34.24 & 40 & 50 & 60 & 50 & 55 & 120 & 60 & 34.24 & 60 \\
\hline$N_{d, i}$ & & 1000 & & & 370 & 380 & 365 & 360 & 365 & 2500 & & \\
\hline
\end{tabular}

Table 2. Initial values $N_{i}(0), \lambda_{i}(0)$, maximum production and incoming rates $\lambda_{i, \max }[\mathrm{MT} / \mathrm{hr}]$, desired inventories $N_{d, i}[\mathrm{MT}]$, and adaptation time $T_{i}[\mathrm{hr}]$.

Note that the initial values for the inventories are near to the desired ones as to generate illustrative curves with small oscillations and fast convergence. Nevertheless the controller can deal with large differences on the initial inventories and productions rates with respect to the desired ones.

The bounds for the control gains were calculated according to Theorems 2 and 3 , such that the gain values (Table 3 ) were chosen inside the corresponding bounds.

\begin{tabular}{|c|c|c|c|c|c|c|c|c|c|c|}
\hline Node & 2 & 3 & 4 & 8 & 9 & 10 & 11 & 12 & 14 & 15 \\
\hline$\alpha_{i}$ & 1 & 2 & 10 & 1 & 2 & 1 & 1 & 1 & 5 & 1 \\
\hline$K_{P, i}$ & 0.1 & 0.9 & 1 & 0.5 & 0.3 & 0.1 & 0.2 & 0.1 & 0.6 & 0.1 \\
\hline$K_{I, i}$ & 0.07 & 0.08 & 0.07 & 0.1 & 0.04 & 0.07 & 0.04 & 0.07 & 0.04 & 0.07 \\
\hline
\end{tabular}

Table 3. Control gain values

Figure 4 presents the inventory levels for producer $N_{3}, N_{9}$, and non producer $N_{4}, N_{10}$ nodes. Note that all inventories converge to their desired values with smooth response. The inventory $N_{9}$ shows higher oscillations than the others during transient $(t<1)$ because it is the node most to the left of the shown ones, such that it is affected by the dynamic changes of all the related downstream nodes. This is the phenomena that origins the bullwhip effect in large supply chains. Notice that the inventories $N_{3}, N_{4}$ implies individual stock levels for the products $\mathrm{A} 1$ and $\mathrm{A} 2$.

From Figures 5 and 6 notice that all rates touch their boundaries at transient and when changes in production from A1 to A2 are required ( $t=5 \mathrm{hrs}$ ), which shows that the physical and operational bounds, equation (4), are held. As a result of changing the production from A1 to $\mathrm{A} 2, \lambda_{3}$ changes its value, while the inventories of the products A1 and A2 converge to their desired values, see Figure 4 . The producer $\lambda_{9}, \lambda_{11}$, and incoming $\lambda_{10}$ rates are shown in Figure 6, where it is shown that $\lambda_{9}$ synchronizes to its demanding rates, with $F_{9,10}=1$ and $F_{9,11}=0.8$. Also notice that $\lambda_{3}$, and $\lambda_{4}$ synchronizes between them accordingly 
to the production ratio $F_{3,4}=1$, see Figure 5. Meanwhile the incoming rate $\lambda_{4}$ synchronizes to the total demand of product A1 of 20 [MT/hr] and A2 of 25 [MT/hr], such that instantaneous consumption synchronization is achieved.

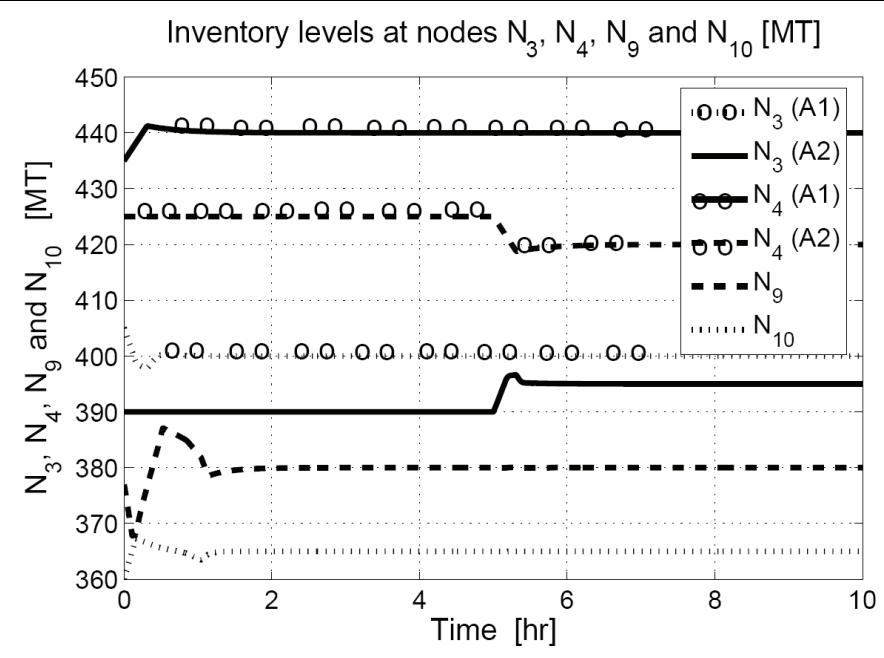

Fig. 4. Inventory levels $N_{3}, N_{4}, N_{9}$, and $N_{10}$.

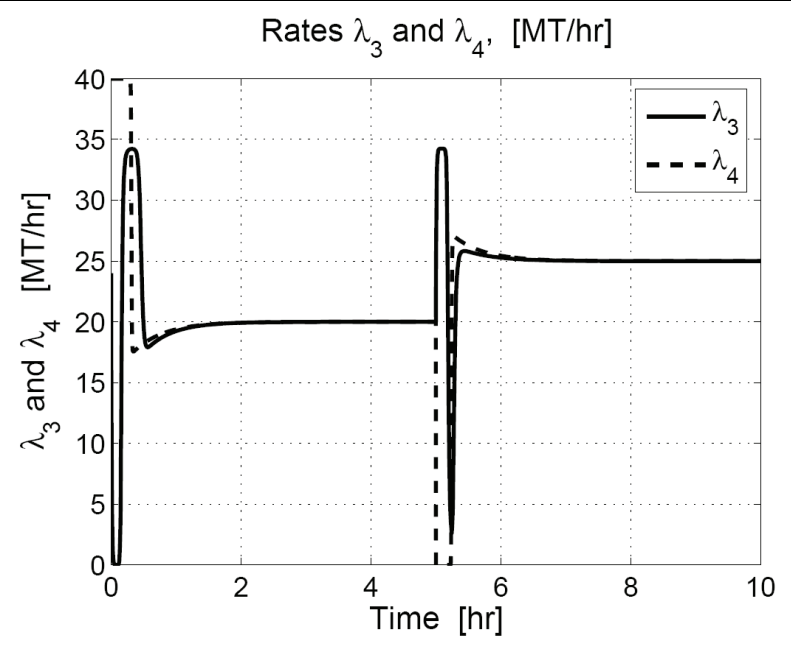

Fig. 5. Production $\lambda_{3}$ and incoming $\lambda_{4}$ rates.

Figure 7 shows a comparison study for different control gains. Note that although the PI control action is filtered by the bounded function, see equations (9), (10) and (11), the behaviour of the PI actions is preserved. A bigger overshoot but faster convergence is obtained when increasing the proportional action and a smaller stationary error is achieved by increasing the integral action. 


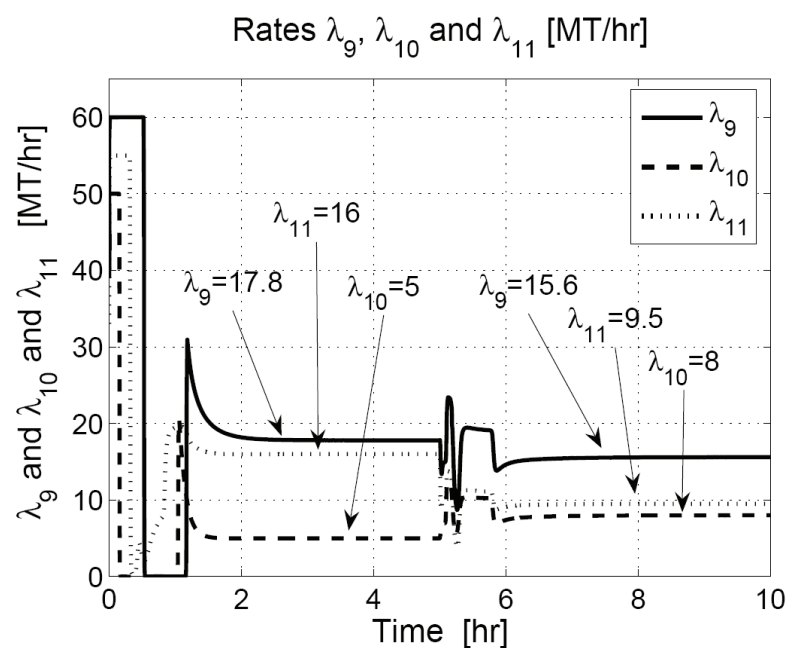

Fig. 6. Production $\lambda_{9}, \lambda_{11}$, and incoming $\lambda_{10}$ rates.

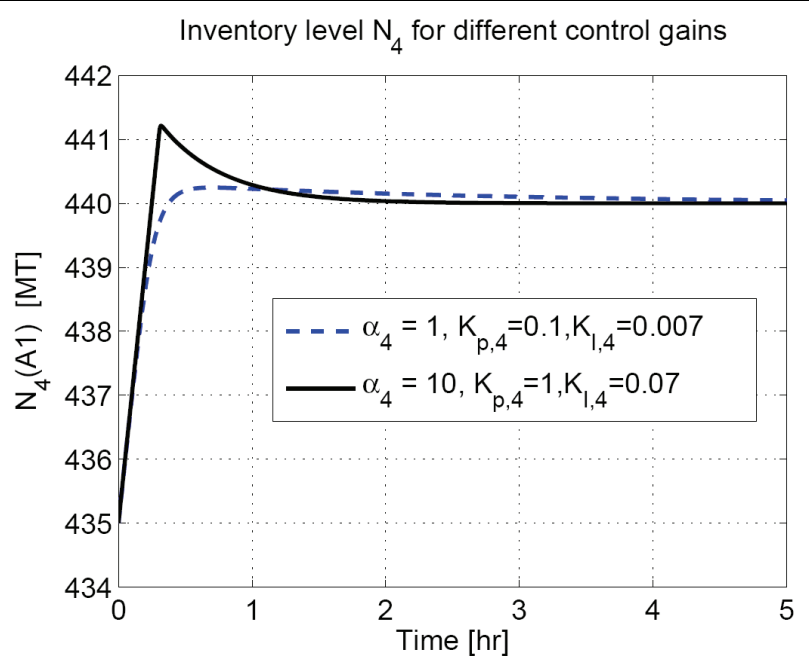

Fig. 7. Comparison study for different gain values.

\subsection{Nonlinear supply chain: crude oil blending and distribution system}

The modelling techniques and controller proposed in Section 2.2 and 3.2 for nonlinear supply chains that consider orders handling are tested by simulations on a blending and distribution crude oil system. The goal is to keep a desired inventory level, while the demanding rate at the distribution side must be satisfied. Figure 8 shows the crude oil supply chain system, where the numbers on the left side identifies the nodes. The initial and desired inventory values in [MT] are listed at Table 4 as well as the adaptation time $T_{i}$ for producers and delay time for processing orders $\tau_{i}$ in [hr]. 


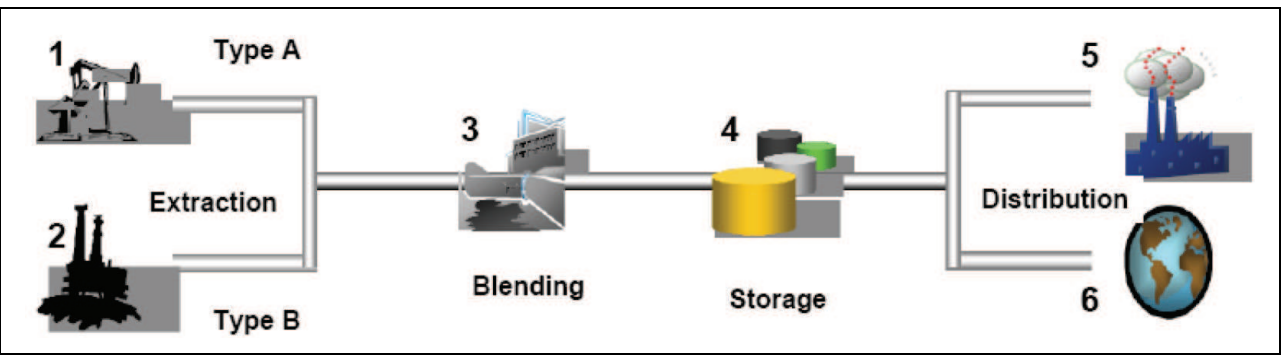

Fig. 8. Extraction, blending and distribution system for crude oil.

\begin{tabular}{|c|c|c|c|c|c|c|}
\hline Node & $N_{d, i}$ & $N_{i}(0)$ & $T_{i}$ & $\tau_{i}$ & $\delta_{i}$ & $\lambda_{i, \max }$ \\
\hline 1 & 8000 & 9000 & & & & 400 \\
\hline 2 & 6000 & 7000 & & & & 400 \\
\hline 3 & 2000 & 4000 & 2 & & & 400 \\
\hline 4 & 3000 & 4000 & & 0.25 & & 500 \\
\hline 5 & 1500 & 2000 & & 0.25 & 150 & 200 \\
\hline 6 & 1000 & 2000 & & 0.25 & 200 & 250 \\
\hline
\end{tabular}

Table 4. Initial values and desired inventories.

The bounds for the control gains were calculated accordingly to Theorems 5 and 6 such that the gain values (Table 5) were chosen inside the corresponding bounds.

\begin{tabular}{|c|c|c|c|c|c|c|}
\hline Node & 1 & 2 & 3 & 4 & 5 & 6 \\
\hline$\alpha_{i}$ & 1 & 0.1 & 1 & 1 & 2 & 1 \\
\hline$K_{P, i}$ & 0.97 & 0.6 & 2.02 & 0.11 & 0.14 & 0.11 \\
\hline$K_{I, i}$ & $3 \times 10^{-6}$ & $3 \times 10^{-6}$ & 0.25 & 0.22 & 0.28 & 0.22 \\
\hline
\end{tabular}

Table 5. Control gain values

Figures 9 and 10 show the results obtained at the closed loop, notice that the inventory levels converge to their desired values, while the control actions follow the demands, thus demands are satisfied. The demand and control actions show the delay introduced by considering traffic flow theory at the dynamic models, nonetheless at steady state they synchronizes each other. Several conditions, such as noise at demands and sudden changes on desired inventories, have been tested by simulations, showing robustness of the closed loop system; however for the brevity of space the plots are skipped. The oscillations during transients at demands and control actions are greatly affected by the delays modelled by $T_{i}$ and $\tau_{i}$, such that bullwhip phenomena can arise.

\section{Conclusions and trends}

Supply chains are challenging systems due to their dynamical behavior, ranging from fast changing demand, transport and delivery delays, inventory management, and production 


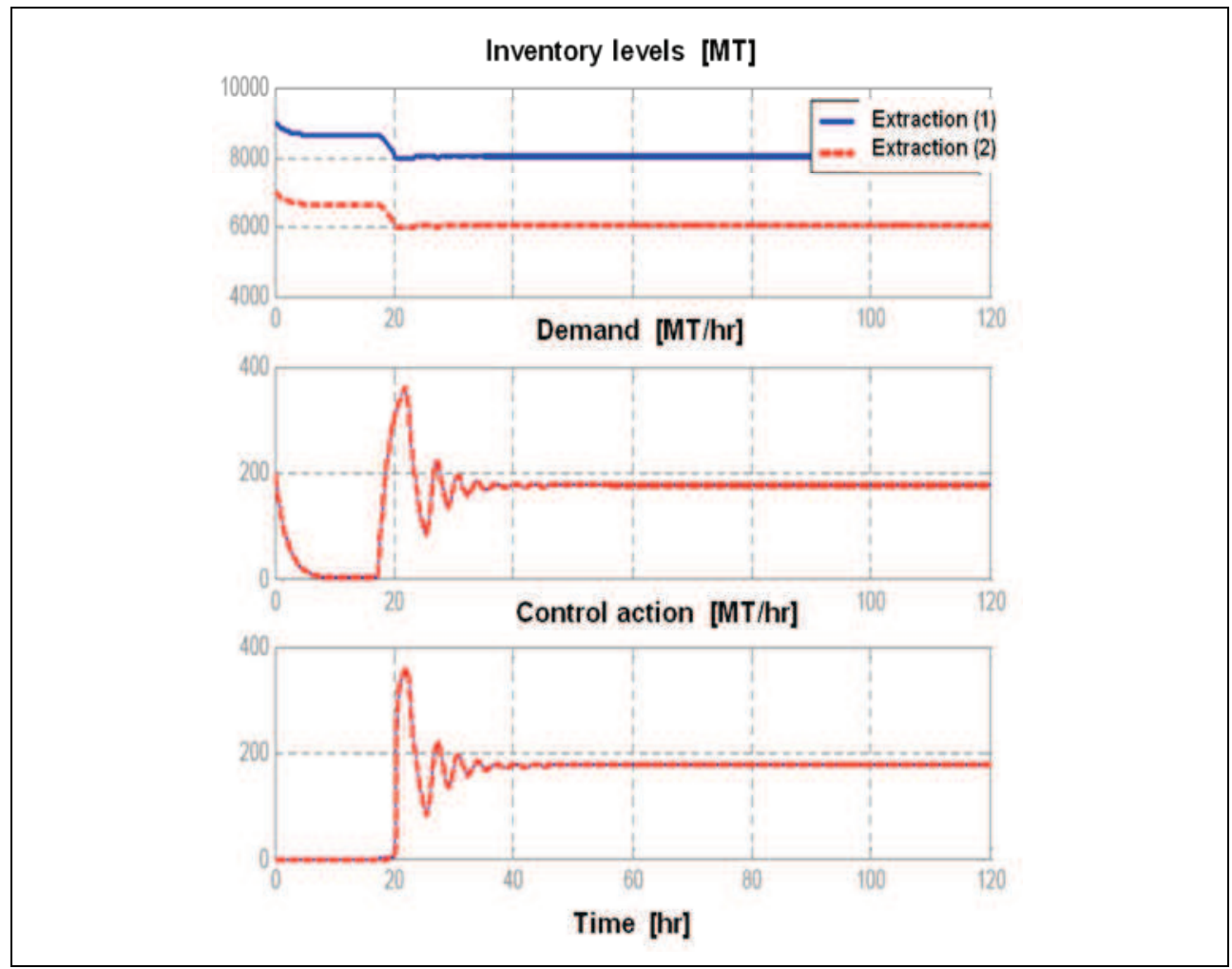

Fig. 9. Supplier nodes 1 and 2.

phenomena. Appropriate control and operation of such systems may contribute to achieve the enterprise objectives.

In this work, the proposed supply chain models go from a simple linear supply chain based on material flows to a nonlinear one considering orders handling and based on traffic flow theory. Nonetheless the simplicity of both proposed models, they reproduced production and transport delays by introduction of time parameters. However, there are several supply chain phenomena that are still to be modeled, such as recycling material loops, hybrid systems with continuous and discrete time dynamics, stochastic behavior, among many others. Differential equation models, as the ones considered here, may be useful on modeling such phenomena, but there are other approaches such as fuzzy sets, neuronal networks, to mention a few, that could be considered.

Furthermore, both the model and control of supply chains must consider the physical and operative constraints. For this purpose, bounded control actions have to be proposed. Several trends on control of supply chains go from classic control theory to time discrete systems, fuzzy strategies and even evolutive algorithms. Due to the type of presented supply chain models it is straightforward to consider classic control techniques such as the PI controllers introduced at this work. An important point when proposing control strategies is the capability of determining stability and operative conditions for the system. 


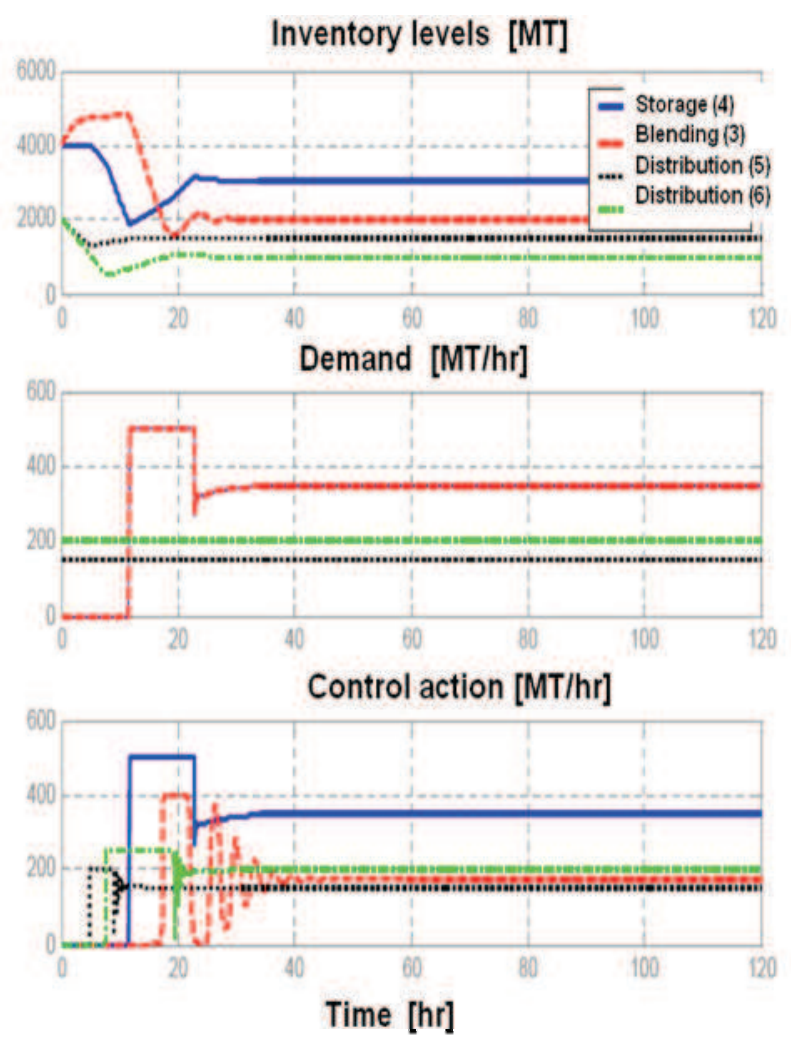

Fig. 10. Nodes 3, 4, 5, and 6 .

This is a key issue to proceed for implementation of the controller to a real supply chain system, otherwise, instability or critical operative conditions may arise. Classic control techniques have the advantage of a well developed variety of stability analysis tools, like pole placement and linearization techniques in which this work is based on to obtain tuning guidelines and stability conditions for the closed loop system.

Simulation study cases have been considered for the purpose of demonstration of the closed loop performance achieved by the proposed models and controllers. In general the simulations allow concluding stability of the supply chain system, convergence of the inventory levels to the desired values and synchronization of the material flows. Thus everything what was predicted by the stability analysis has been confirmed by the simulation case studies. Although comparison and analysis of simulation results are valid to draw some conclusions, development of scale models or prototypes has to be considered for a better understanding of supply chains and more realistic implementation of the controllers and management strategies of such systems. 


\section{References}

Cetinkaya, S., \& Lee, C., (2000). Stock replenishment and shipment scheduling for vendor managed inventory systems, Management Science, 46, 2, electronic ISSN 217-232, 217-232.

Daganzo, C.F. (2002). A Theory of Supply Chains, Springer-Verlag, ISBN: 3-540-00288, Berlin, Germany.

Dunbar, W.B. \& Desa, S. (2005). Distributed Model Predictive Control for Dynamic Supply Chain Management, Int. Workshop on Assessment and Future Directions of NMPC, Freudenstadt-Lauterbad, Germany, August, 26-30.

Fujimoto, H. (2002). Supply chain for the synchronization of production and distribution. Osaka Keidai Ronshu, 53, 3, 307-315.

Helbing, D., (2003) Modeling supply networks and business cycles as unstable transport phenomena. New Journal of Physics, 5, 90, ISSN 1367-2630, 90.1-90.28.

Helbing, D., Lämmer, S., Seidel, T., Seba, P. \& Platkowski, T. (2004). Physics, stability, and dynamics of supply chain networks. Physical Review E, 70, 6, 066116(1-6), ISSN: 1550-2376.

Koudal, P., (2003). Integrating demand and supply chains in the global automotive industry: building a digital loyalty network at General Motors. Deloitte Research and Stanford Global Supply Chain Management Forum, Research article, www.dc.com/research

Koudal, P., \& Wei-the ,V. L., (2005). The power of synchronization: the case of TAL Apparel Group, Deloitte Research, Research article, www.dc.com/research

Lababidi, H., Ahmed, M., Alatiqi, I., \& Al-Enzi, A., (2004). Optimizing the supply chain of a petrochemical company under uncertain operating and economic conditions, Industrial \& Engineering Chemistry Research, 43, 1, ISSN: 0888-5885, 63-73.

Lefeber, E., (2004). Nonlinear models for control of manufacturing systems, Nonlinear dynamics of production of production systems, Ed. G. Radons and R. Neugebauer, ISBN: 3-527-40430-9, 71-83.

Lin, P., Wong, D., Jang, S., Shieh, S., \& Chu, J., (2004). Controller design and reduction of bullwhip effect for a model supply chain system using z-transform analysis, Journal of Process Control, 14, 5, ISSN: 0959-1524, 487-499.

Nagatani T. \& Helbing, D. (2004). Stability analysis and stabilization strategies for linear supply chains. Physica A, 335, 3-4, 644-660, ISSN: 0378-4371.

Perea-Lopez, E.; Grossman, I.E., Ydstie, B.E. \& Tahmassebi, T. (2001). Dynamic Modeling and Decentralizes Control of Supply Chain. Ind. Eng. Chems. Res., 40, 15, 3369-3383, ISSN: 1520-5045.

Perea-Lopez, E., Ydstie, B.E. \& Grossman, I.E.; (2003). A model predictive control strategy for supply chain optimization. Comp. E Chem. Eng., 27, 15, 1201-1218, ISSN: 00981354.

Petrovic, D., Roy, R., \& Petrovic, R., (1999). Supply chain modeling using fuzzy sets, International Journal of Production Economics, 59, 1-3, ISSN: 0925-5273, 443-453.

Shapiro, J. F. (2007). Modeling the Supply Chain. Duxbury Thomson Learning Onc., ISBN: 0495-12611-x, h., Pacific Belmont CA. 
Steidmann, C. (2004). Synchronicity: an emerging vision of the retail future. Deloitte Research, Research Brief Report, May, www.dc.com/research.

Tayur, S., Ganeshan, R., \& Magazine, M., (1998). Quantitative models for supply chain management, Boston, Kluwer Academic Publishers, ISBN: 0-7923-8344-3. 


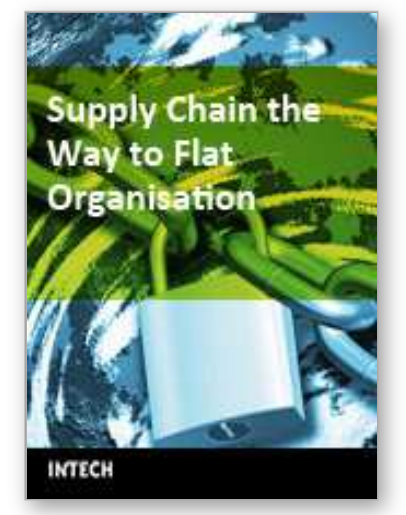

\author{
Supply Chain the Way to Flat Organisation \\ Edited by Julio Ponce and Adem Karahoca
}

ISBN 978-953-7619-35-0

Hard cover, 436 pages

Publisher InTech

Published online 01, January, 2009

Published in print edition January, 2009

With the ever-increasing levels of volatility in demand and more and more turbulent market conditions, there is a growing acceptance that individual businesses can no longer compete as stand-alone entities but rather as supply chains. Supply chain management (SCM) has been both an emergent field of practice and an academic domain to help firms satisfy customer needs more responsively with improved quality, reduction cost and higher flexibility. This book discusses some of the latest development and findings addressing a number of key areas of aspect of supply chain management, including the application and development ICT and the RFID technique in SCM, SCM modeling and control, and number of emerging trends and issues.

\title{
How to reference
}

In order to correctly reference this scholarly work, feel free to copy and paste the following:

Alejandro Rodríguez-Angeles, América Morales Díaz and Arturo Sánchez (2009). Dynamic Analysis and Control of Supply Chain Systems, Supply Chain the Way to Flat Organisation, Julio Ponce and Adem Karahoca (Ed.), ISBN: 978-953-7619-35-0, InTech, Available from:

$\mathrm{http}: / /$ www.intechopen.com/books/supply_chain_the_way_to_flat_organisation/dynamic_analysis_and_control _of_supply_chain_systems

\section{INTECH}

open science | open minds

\author{
InTech Europe \\ University Campus STeP Ri \\ Slavka Krautzeka 83/A \\ 51000 Rijeka, Croatia \\ Phone: +385 (51) 770447 \\ Fax: +385 (51) 686166 \\ www.intechopen.com
}

\author{
InTech China \\ Unit 405, Office Block, Hotel Equatorial Shanghai \\ No.65, Yan An Road (West), Shanghai, 200040, China \\ 中国上海市延安西路65号上海国际贵都大饭店办公楼405单元 \\ Phone: +86-21-62489820 \\ Fax: +86-21-62489821
}


(C) 2009 The Author(s). Licensee IntechOpen. This chapter is distributed under the terms of the Creative Commons Attribution-NonCommercialShareAlike-3.0 License, which permits use, distribution and reproduction for non-commercial purposes, provided the original is properly cited and derivative works building on this content are distributed under the same license. 